\title{
The Climate of the Shinjo Basin viewed from its Rice-plant Seeding Season
}

\author{
Hiroshi SHITARA
}

\section{Introduction}

It is quite natural that, climatologically examined, a series of basins situated in a row in the western half of the Tohoku Region should have the characteristcs of their own, but at the same time show a climatic community with one another, which is quite different from that of coastal plains. ${ }^{(1)}$ If such a climatic community can be permit'ed to be named "basin climate", the Shinjô Basin yet has its peculiar attributes, and raises some problems of interest. One of them is a considerably low air temperature in spring.

In the Tôhoku Region where cultivable season is very brief, the earlier they seed, the more crop is harvested. Seeding or transplanting rice-plants 4 or 5 days later than due time causes a severe influence upon its crop. This is a generally recognized fact. That is to say, when a view-point is focussed on the rice-plant seeding season in this region, two groups of climatic conditions contradicting each other can be extracted, and the seeding season and the local characteristics of the agricultural technique seem to be of great interest, because one is thought to express the result from the contradiction of these two groups, and the other to be caused by the unfavourable climatic conditions.

The author's thanks are due to Prof. Tomita for his kind direction, to Prof. Miyagawa and Assist. Prof. Tanabe for their incessant encouragement; and Messrs. Fukui, Takeuchi, Watanabe and Shigihara, who were willing, at any time to take part in the discusston with the author.

\section{A few climatic conditions making seeding earlier}

(1) Untsability of air temperature in early summer

A considerably high temperature is required for rice-plants to grow and

(1) The author intends to take up this subject in future.

(2) H. Shitara : On a lower air temperature in spring. (made public at the meeting of Tohoku Geographical Association, Sep. 1952) 
the natural coming out of the seeds is regarded to be difficult in a greater part of the Tohoku Region. ${ }^{(3)}$ But, though this handicap can be overcome by the method of seeding after artificial sprouting and the technique of a rice nursery management, ${ }^{(4)}$ yet the weak point in the temperature in spring causes frepuent damages to the Tohoku Region. ${ }^{(5)}$ This makes the author understand that the seeding time means very much to its crop. ${ }^{(6,7)}$ That is to say, even 4 or 5 day's delay brings a fatal result. ${ }^{(8)}$ Early seeding and early transplanting are forced even in an ordinary year in Tohoku, where accumulating temperature is low. In the districts south of Kanto, the seeding season lasts till the beginning of May, while in Tohoku it only does till the end of April. Especially, the Mogami Basin is more often exposed to the coolness of early summer than any others in Tohoku. ${ }^{(9,10)}$ Moreover, this is one of the areas that are damaged most severely by summer coolness in the western. half of north-eastern Japan. Here fies a climatic condition which forces those who are in this area to seed specially earlier. (11)

(2) Earlier visit of autumn

In addition to the above condition, the area is earlier visited by the wet season of autumn, ${ }^{(12)}$ and this phenomenon is more conspicuous around the basin. ${ }^{(13)}$ In respect of a drying method after the harvest of rice, which is seen different according to a district, the following two kinds are now prevalent in the

(3) (4) Y. Noguchi : Some problems concerning agricultural Location. Agciculture and Horticulture. Vol. 27, p. 510.

(5) T. Asai : On the distribution of air temperature in Tohoku District when "Yamase" cold wind prevails. Miscellaneous Reports of the Research Institute for Natural Resourses. No. 16.

(6) Bureau of Agricultural Affairs, Department of Agriculture and Forestry : The state of the damage given to the rice-plants 1934 .

(7) Agricultural Section, Department of Agriculture and Forestry: A report on the state of the damage given to the rice-plants in the Tohoku region; 1935

(8) H. Terao : An outline of the damage given to rice-plants by summer coolness. Agriculture and Economy. Vol. I, 1942.

(9) H. Shitara : The monsoon and air temperature in the Tohoku region. The Report of Geographical Inst., Faculty of Science, Tohoku Univ. (in Japanese) No. 1.

(10) K. Oasawara: The climate of Yamagata Pref. 1951.

(11) The diligent farmers are gradually trying to make the seeding time earlier.

(12) H. Shitara : A Hythergraph in the Tohoku Region. (The treatise for promotion at Tohoku Univ.)

(13)(21) H. Seitara: The Local colour expressed by climatic phenomena in the middle part of the Tohoku Region. Vol. II. (Graduation thesis at Tohoku Univ.) 


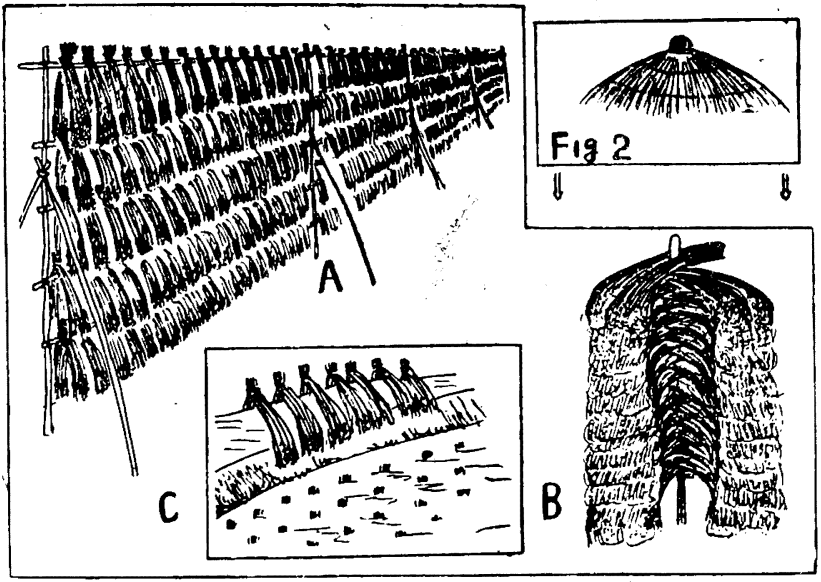

Fig. 1 Rice-plant drying Methods A': Hase-gake B : Kui-gake C: Aze-tate

Fig. 2 Straw-made Umbrella

area, "Hase-gake" method and "Kui-gake" method. (Fig. 1) The former can be found in the middle part of the basin, and the latter, south of Ashizawa and Shio on the south; west of Kamabuchi on the north and from Osawa on the west, the boundary being traced clearly.

Generally speaking, "Kui-gake" method is frequently seen in the plain, while "Hase-gake" method among the mountainous areas, and the drying method is thought to depend upon the materials obtainable. Furthermore, one more general idea goes, which explains that the difference of the drying methods according to the area is due to the grade of the drying technique. Prof. Nagai is of an opinion that "Hase-gake" prevailed throughout the Mogami Basin in former times, but later, "Kui-gake" adopted in the Yamagata Basin began to spread out into the Shinjo Basin; that the wave has covered its middle part; and that the propagation front now lies on the boundary line between "Kui-gake" and "Hase-gake" methods. (14) His standpoint is obviously not a physical one, but a historical one. But the author can not understand this border line without taking the climatic conditions into consideration for the following reasons.

Roughly speaking, Japanese have had five ways of drying paddy. "Hasegake", mentioned above, is one of them. They dry the rice-plants by hanging them over the several bars laid across in parallel between the logs put into the earth at the same interval (A type). "Kui-gake" is a way of stacking the rice-

(14) In the discussion with the author. 
plants around a $\log$ put into the fields or into the foot-paths between the fields (B type). "Azetate" dries them as Fig.1 shows (C type). Putting them directly on the surface of the paddy-fields is another way (D type), and the way to spread the paddy on "Mushiro" (straw mattings) after reaping is also adopted popularly (E type). Let the author cite some examples, from "the diary of the meeting for mutual talking of agricultural affairs" (Nodan-kai-nissi), ${ }^{(15)}$ published in 1881. E and D tpyes, it reports, seem apt to have prevailed in comparatively warm and dry districts in Japan, while A type to have been adopted in the wet districts with wet and soft paddy-fields. It showed one example in Yamanashi Pref., saying that they had used A type, but began to take another way because dryness was not enough in this way which caused rotteness about April and May. It also said about a case in Ishikawa Pref. that D type prevailing in the area was not good enough to dry the rice-plants and that A type was recommended, though it required much trouble; and that $D$ type was the way to be adopted then in Nagano Pref., where "Hase-gake" was recommended as an improved drying method. The author can also find another example of Iwate ,Pref. in the diary. There both $\mathrm{A}$ and $\mathrm{B}$ types, were seen, it reports, but D type is dominant owing to the troublesome structure of A type, while in Niigata Pref., being wetter in winter and autumn, B and D types brought worse results than A type. And he can cite one more case in Akita Pref., in which "A type is the most excellent of all, because B type brings incomplete dryness."

Such cases as the author cited above, do not covince him that "Hasegake" is destined to be improved toward "Kui-gake" in the swampy districts, to say the least of it. Furthermore, in a coastal district in Shimane Pref., they substitute ropes for the bars of "Hase-gake" for it is quite far from the woodland, and they can hardly obtain any materials. This fact can be a powerful evidence proving that the material can not always have any infuence upon a drying method.

Osawa Settlement in the western part of the Mogami Basin lies just on the boundary between the "Hase-gake" area and "Kui-gake" one, and these two types are seen co-existing there. According to the result of a survey concerning the use of "Wara" (straw) after thrashing, the straw of "Kui-gake" is too wet to be used for anything but the vegetable manure heap. On the contrary, straw rice-bags and mattings are made chiefly of the straw used in "Hase-gake",

(15) Bureau of Agricultural Affairs : A Diary of the meeting for mutuil discussion of Agricultural Affairs. 1881. 
which makes the plants dry completely. ${ }^{(16)}$

Every stack (Kui-gake), moreover, is seen to be covered on top with a kind of straw-made umbrella, lest frequent drizzling showers in autum should make it drenched (Fig.2). This may be called a kind of climatic landscape and means that the climatic condition no longer permits "Kui-gake" to be adopted as a method of drying rice-plants. In other words, the paddy dring period is regarded to thrust itself into the wet season of autumn. ${ }^{(17)}$ For this reason, the drying is forced to be shortened and accordingly, the seeding one to be made earlier, especially in the zone around the basin.

3) Based on what the author mentioned above, it may be drawn that the climate in spring and autumn is an unfavourable condition which presses the district to begin its agricultural work, that is, to seed the rice-plnats earlier.

\section{Climatic conditions preventing earlier seeding}

Then, does the climate of spring permit the earlier seeding the climate of summer and autumn demands? An extra-ordinarily low temperature in spring can be regerded as one of the climatic conditions to prevent seeding. Mr. Kato has already noticed the characteristics of temperature in his comparison between the temperature of Yamagata and that of Shinjo ${ }^{(18)}$, and Mr.Tôya attributed it to the shortage of sunlight. ${ }^{(19)}$ But, the author hesitates to agree with Mr.Toya, though he only succeeded in solving the same problem partially in his study and there still remains some points left unsolved. ${ }^{(20)}$

By the way, this low temperature has hindered the growth of the young rice-plants, and accordingly, prevented earlier seeding. It is clearly observed that even now they have difficulty in growing them in the open fields; they have their seed-beds among the houses to protect the young rice-plants from the cool find, making good use of the sunny spots found on the south side of the houses. One will meet with an outstanding landscape constituted by the houses and seed-beds lying alternately along the roads.

The Shinjo Basin is one of the most snowy districts in the western half

(16) This tendency can be observed in the "Kui-gake" area lying in the middle part of the basin. "Hase-gake" found at some places are put for the straw of good quality.

(17) A conspicuous example can be found in Ishikawa Pref. The diary(15) says, "It snowed during the drying season and the peasants there were obliged to gather in the rice-plants."

(18) T. Kato : The characteristics of physical conditions in the Mogami District. (Yamagata Pref.) 1952.

(19) A report by Toya. (unpublished) 
of Tôhoku ${ }^{(21)}$ and also one of the latest thawing ones in Japan. ${ }^{(21)}$ Comparing the mean temperature of a Gun with that of another, - the mean value was] got from the observation values obtained at the towns and villages in every Gun in $1934^{(22)}$ _ t the author finds there were only $3 \mathrm{Gun}$ that were more snowy than MogamiGun among 74 Gun in Tohoku. Fig. 3 shows the distribution of

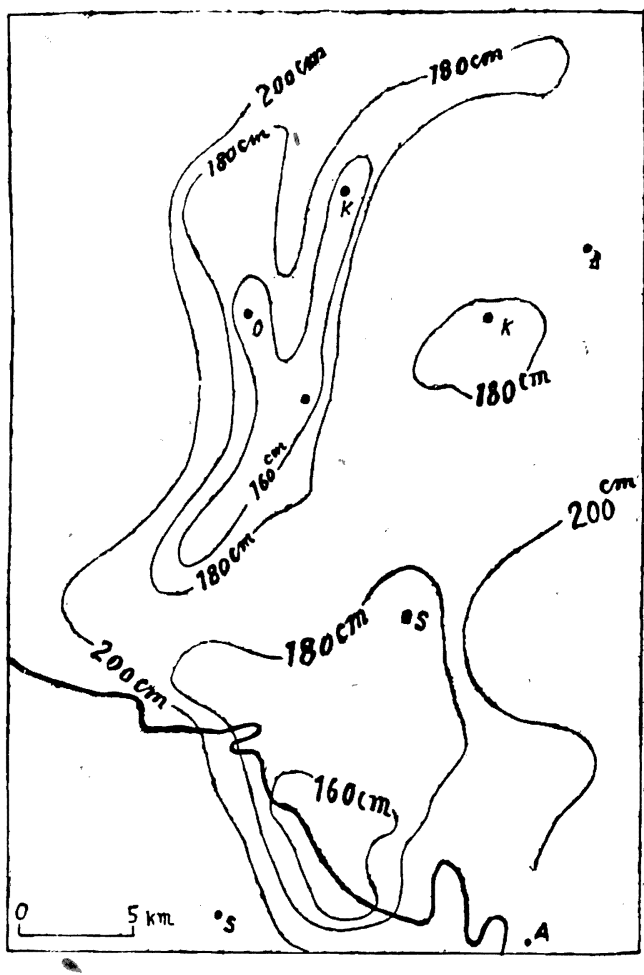

Fig. 3 Distribution of Snowfall on Feb. 25th, 1934 snowfall, the value being got by measuring at the same time on Feb. 15th, 1934. The low temperature in Spring, accompanied with the much snow shown in the figure, forms socalled "bad circulation" with later thawng, causing a great hiderance to seeding. That is to say, it is not rare that the snow still covers the fields even in the flat lands, though, a farming season comes round. The materials in 1934 show that only two Gun were later than MogamiGun in thawing in Tôhoku.

The low temperature and later thawing in spring are conspicuous to such a degree as above, and naturally prevent the growth of the young rice-plants and also seeding. Here occurs a serious difficulty. That is, the climatic condition in summer and autumn forces earlier seeding on the one hand, and the condition in spring hinders the demand on the other hand. It is under these contradictory climatic conditions that they are now toiling to seed the plants in the district.

IV A relation between the seeding and thawing seasons viewed from distribution

The author has managed to draw a distribution map of the rice-plant

(21) H. Shitara : On the Distribution of Snowfall in Japan. (Promotion treatise at Tohoku Univ.)

(22) The Survey Institute of Agricural Household Economy in the Snowy Districts ; Annual Report on the Results of Survey. 1935. 
seeding time both by a synthetic interview research and based on the diaries of the diligent farmers Idurng his 1953's survey, (Fig.5) being able to ascertain the

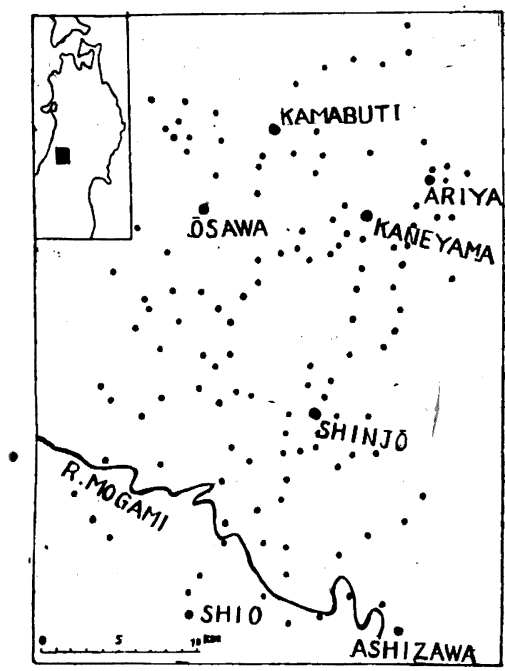

Fig. 4 Index Map

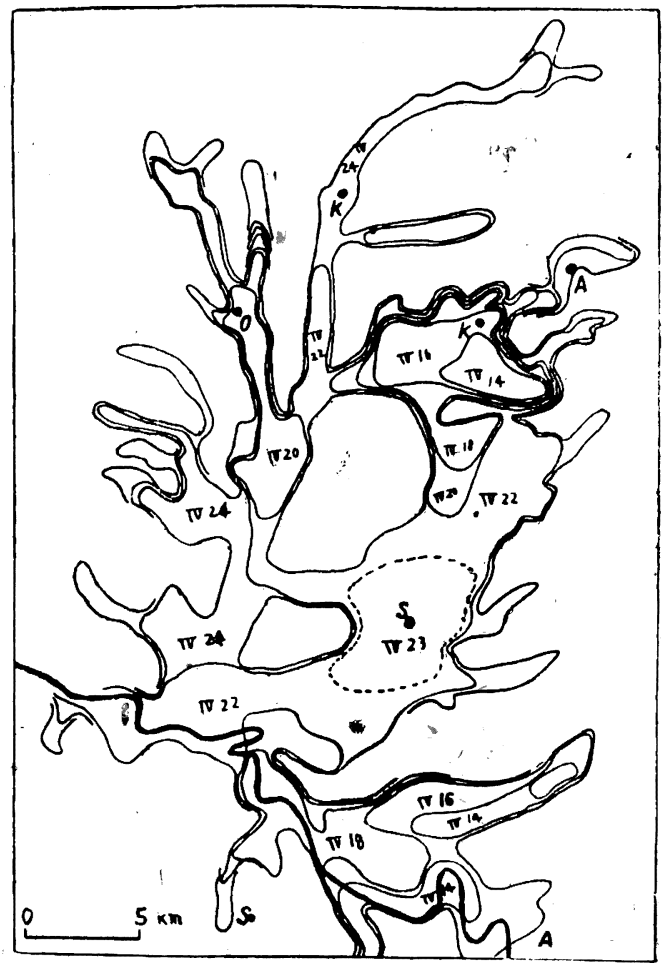

Fig 5 Distribution of Rice-plant seeding time

average of the complete thawing time of successive years at the same time. The hearing method was put into practise at about 120 settlements. (Fig.4) The question is "How many days later or earlier do you seed the plants and does the snow melt than 10 or more places around?" He asked the question of several persons at every settlement. In this way, the thawing and seeding times were decided synthetically. He also took other materials into consideration. ${ }^{(23,24)}$ Fig. 6 is the distribution map of the thawing time.

When a comparison is made between the two distribution maps, there seems no relation with each other at a glance, but a closer observation will reveal the following fact. In the western part of the basin, a correlation of distribution

(23) The Materials from Meteo. Obsev.

(24) M. IMAI : A Study on the Prevention of Agricultural Damages and its Effect. 1951.

(for example) 


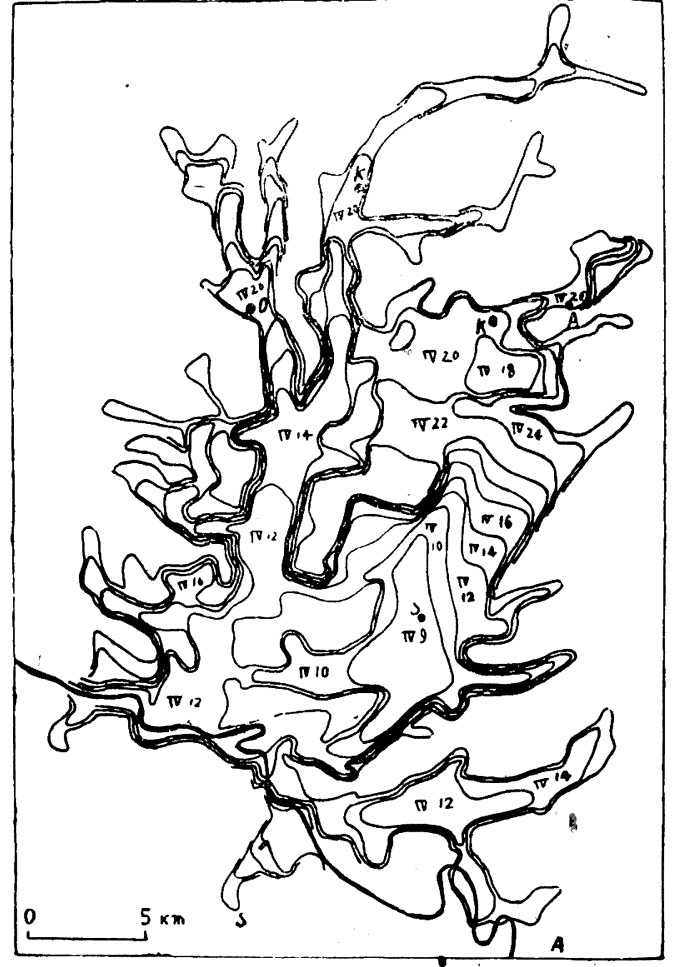

Fig. 6 Distributioin of Thawing Season can be evidently shown there. But in the eastern part, on the contrary, the later the snow of a place melts, the earlier they seed; and the farther is a point situated from Shijô, the later the snow thaws there and the earlier they seed. In this case, a negative correlation of distribution is discerned. Thus, it has been made clear that the eastern part is quite differrent from the western part in the correlation between them, and that the maps, completely independent and different in outward appearance, are connected by a correlation, positive or negative.

\section{A geographical meaning of the negative correlation of distribution}

As Fig.5 and 6 show, there are a number of areas where seeding is antecedent to thawing in this basin. This is not only why the climatic conditions in summer and autumn press them to seed earlier but also why, in the snowy districts, the young rice-plants grow to be weak and to be subject to various kinds of diseases, resulting in a poor harvest when they prepare the seed-beds after natural thawing. Consequently, they are forced to do so by adopting an artificial thawing.

Now let the author dot every point on the co-ordinates $x y$, the thawing time being $\mathrm{x}$ and the seeding time $\mathrm{y}$. (Fig.7) Then, the points where $\mathrm{x}=\mathrm{y}$ can be found on the line $y=x$. If the preparation of seed-beds is begun 10 days earlier than seeding, the points where the time for the preparation coincides with that of thawing will be on the line $y=x+10$. As the line $x=y$ has a fundamental meaning as to whether the remaining snow causes a direct hinderance to 


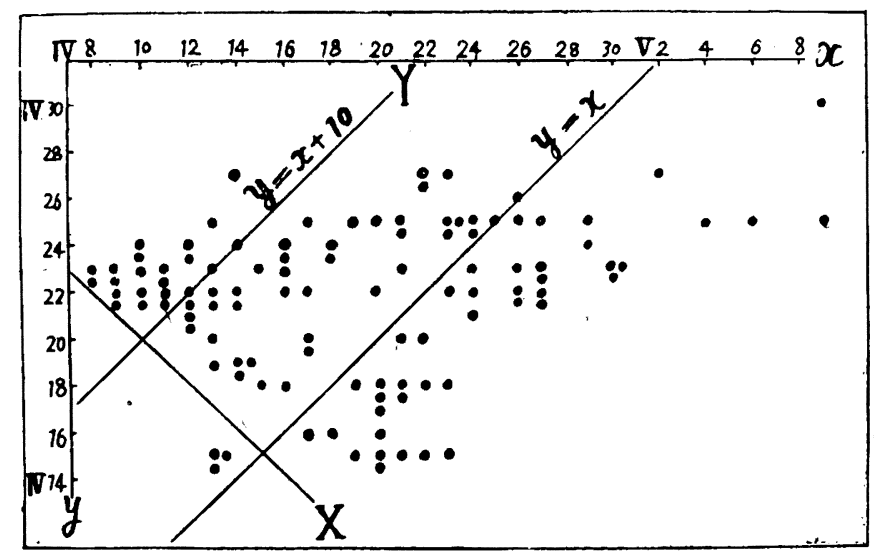

Fig. 7

the paddy growing or not, the author makes it $\mathrm{Y}$ axis and draws $\mathrm{X}$ axis crossed at $90^{\circ}$ to $\mathrm{Y}$ axis. Then the plus value of $X$ shows the number, of days between the beginning of the work and natural thawing, and $X$ value means the one that ought to have relation with artificial thawing. Fig.8 is the graph of distribution of $\mathrm{X}$ values, which shows a considerable variety in every area.

Dr. Hirata once concluded concerning the "artificial thawing in this district that scattering ash or earth made thawing earlier by more than 10 days, and that the water irrigated from the springs and rivers produced a conspicuous effect on thawing. ${ }^{(25)}$ Since then, these methods have been being encouraged in the

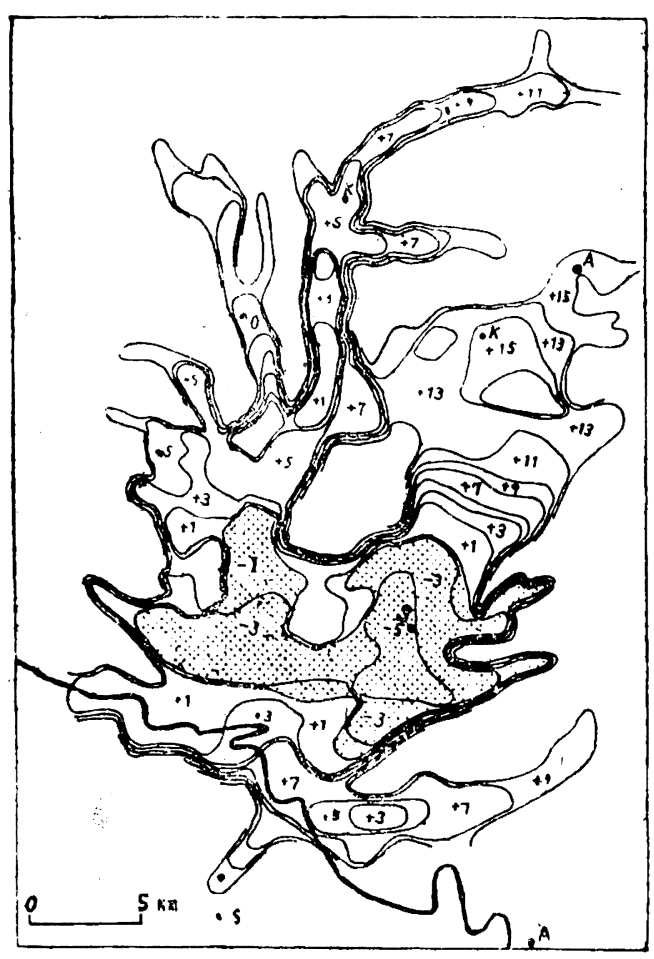

Fig. 8 Distribution of $\mathrm{X}$-value

(25) T. Hrrata : A Study on Thawing. Annual Reports of the Survey Institute of Agricultural Household Economy in the Snowy Districts. 1935 
areas where thawing is later, and adopted by some where they have no little interest in rice-plant farming. That is to say, many of the places, where less than $x=0$ in Fig.7, don't take up the means of artificial thawing, while at the points where $8>x>0$, they sprinkle ash or earth chiefly. At the places where $13>x>8$, furthermore, the water is introduced into the seed-beds in winter, and where $x>14$, the snow is dug out, carried away and then, the seed beds are prepared on the very spot. When there is a heavy snow, the last method is adopted throughout the basin. The seeding time in the eastern part, which does not correspond with the thawing time, contrary to the western part, shows close correlation with the stage of an artificial thawing work. That is to say, in the eastern area, the $\mathrm{x}$ value increases conspiucously in proportion to the distance toward the north. In other words, those in the northern part where thawing is later, seed the plants earlier than those in the southern part. This fact means that the former prepares against the unfavourable climatic condition in summer and autumn, quickening artificially the thawing in spring when it may be possible that the difficulty is overcome technically.

The negative correlation can be understood as above. And such a correlation is traced from Shinjo to Kaneyama. As we go up toward the north from Kaneyama to Ariya, the speed of thawing begins to slow down rapidly, and the thawing time grows earlier. Here the correlation is broken, and the negative one appears. In other words, at the points north of Ariya, they can not resist too much remaining snow and colapse under the climate of autumn.

A great gap of the seeding time found between the Ariya and the Kaneyama areas, makes the difference of the transplanting time wider, resulting in flowing of the labour the Ariya area keeps into the Kaneyama area in its transplanting time. The peasants from Ariya receive the young rice-plants instead of their wages and return home to plant them in the paddy fields of their own. This is the reason why the severe climatic condition in spring in the Ariya area prevents the seedlings from growing to be stout and the unstability of climate causes a severe damage. That is to say, growing rice-plants in this area means nothing but the way to get enough food for a single family to be hardly supported, and they are economically forced to lay stress upon such subsidiary works peculiar to mountain villages as charcoal production and others. When the area is compared with Kaneyama where they can wholly depend for their livings upon rice cultivation, a clear boundary line may be supposed between these two areas. 


\section{Conclusion}

As above, the farmers in the Shinjo Basin show various attitudes toward the climatic conditions in the seeding season according to their desire for production and the agricultural technique of their own. A correlation of the natural thawing time with the grade of the artificial thawing work adopted can be made clear by the points dotted in the correlation graph, the vertical axis being $\mathrm{X}$ and the horizontal one x. (Fig.9) In the figure, a tendency can be observed of the

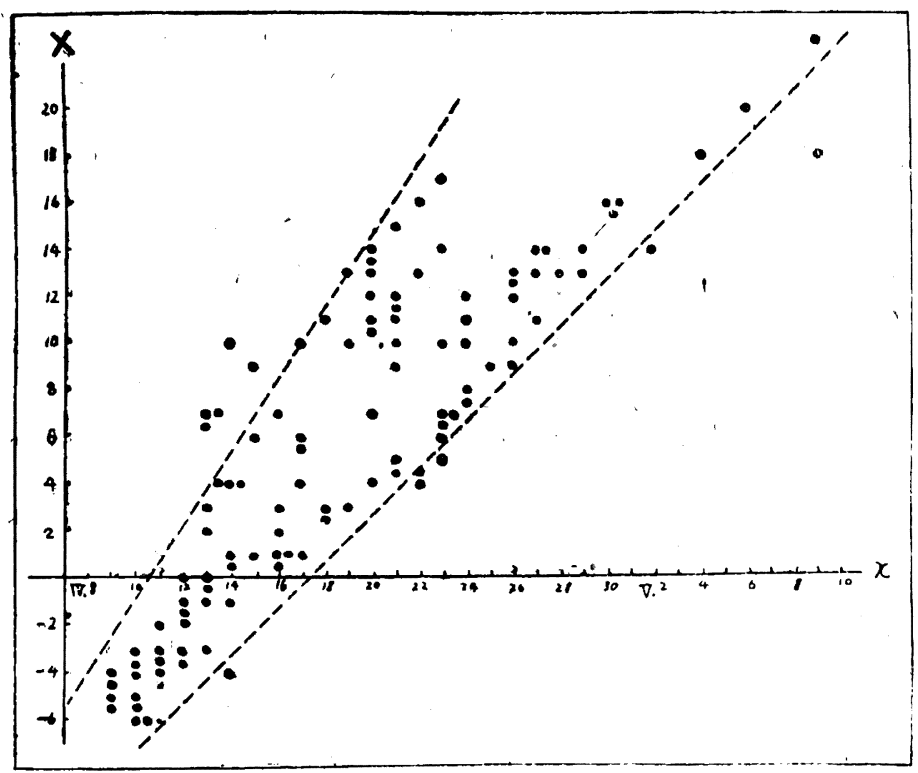

Eig. 9

increse in $\mathrm{X}$ values in proportion to the delay of $\mathrm{x}$, and a clear lower limit-line is noticeable in parallel to the above tendency. This means the increase in $\mathrm{X}$ values which they are forced to show against later thawing so long as they are engaged in paddy growing, and the lowest limit-line of the artificial thawing work that the climatic condition in summer and autumn presses on the basin. Every point above this boundary-line reveals that the farther it lies from the lower limit-line, the earlier must it begin to prepare the seed-beds, overcoming the difficulty in spring. Moreover, the upper limit-line can also be drawn in the graph and convinces the author that the climatic condition does not permit the points above the boundary-line to grow paddy in the present stage of the agricultural technique. In other words, it is perfectly possible to regard the seeding season in the Shinjô Basin as the space between the upper limit and the lower 
limit lines, one caused climatically by spring and the other by summer and autumn. The author may, therefore, conclude that this very space shows the climatic conditions in this district viewed fron its seeding seeson, suggesting an angle from which the climate of a district may be grasped. 